\title{
AVALIAÇÃO DO POTENCIAL DE REUSO AGRÍCOLA DO EFLUENTE DE UMA ESTAÇÃO DE TRATAMENTO DE ESGOTO COM ALAGADOS CONSTRUÍDOS
}

\author{
Giselda Passos Giafferis ${ }^{2}$, Zacarias Xavier De Barros $^{3} \&$ Eduardo Luiz De Oliveira ${ }^{4}$
}

\begin{abstract}
RESUMO: A pesquisa foi realizada na estação de tratamento do Departamento de Água e Esgoto de Bauru, localizada no Distrito de Tibiriçá, com vazão média na entrada da estação de 4,8L/s, composta por filtro anaeróbio de fluxo ascendente, seguido de sistemas de alagados construídos em paralelo. Como objetivo deste trabalho, avaliou-se a eficiência dos três sistemas de alagados construídos, com tipos de plantas diferentes (Lírio do charco, Papiro gigante e Taboa) e analisou-se quantitativa e qualitativamente, os efluentes nas várias etapas do processo de tratamento, para verificar suas eficiências e a possibilidade de reuso do efluente final na agricultura. Diante dos resultados obtidos, observou-se que houve satisfatória remoção de matéria orgânica, com concentração média de 36 e $39 \mathrm{mg} / \mathrm{L}$, nas Fases 1 e 2 de operação, respectivamente. Constatou-se que as concentrações de nutrientes, como nitrogênio e fosfato foram altas em todo o sistema e a eficiência de remoção de nitrogênio amoniacal esteve muito abaixo do esperado, concluindo que o sistema de alagados está funcionando como tratamento secundário e não como terciário. As concentrações de micro-organismos encontrados no efluente final foram elevadas. Portanto, conclui-se que os resultados de eficiência de remoção da matéria orgânica, dos sistemas de alagados construídos atendem aos parâmetros exigidos pelas legislações para lançamentos de efluentes e não atendem para nitrogênio e micro-organismos, mas se adequam para fins de reuso na irrigação restrita na agricultura.
\end{abstract}

PALAVRAS-CHAVE: Alagados construídos, tratamento de esgoto, wetlands construídos, reuso.

\section{EVALUATION OF THE AGRICULTURAL REUSE POTENTIAL OF A SEWAGE TREATMENT PLANT BUILT WITH CONSTRUCTED WETLANDS EFFLUENT.}

\begin{abstract}
The study took place in a sewage treatment plant located at the actual Department of Water and Sewer in Bauru, city of Sao Paulo state. This treatment plant has an average entrance flow of 4.81 . s- 1 made by upflow anaerobic filter, followed by wetland systems constructed in parallel. . As objective of this study we evaluate the effectiveness of three systems of constructed wetlands, with three different types of plants (Lily pond, Giant papyrus and Cattail),quantify, and qualify the effluents at various stages of treatment to monitor their effectiveness and the possibility of reuse in agriculture. There was a satisfactory removal of organic matter, with a mean concentration of 36 and 39mg.l-1 at the , phases 1 and 2 of the operation, respectively. The constructed wetlands effluent nitrogen and phosphate concentrations were high throughout all the system and the removal efficiency of ammonia nitrogen was much lower than expected, then the system is functioning as secondary treatment and not as tertiary treatment. The concentrations of micro-organisms found in the final effluent were also high. Therefore, it is concluded that the results of removal efficiency of organic matter, of constructed wetland systems, meet the parameters required by legislation for effluent discharges but do not attend the parameters required for nitrogen and micro -organisms. This way, these analyzed plants effluents are suitable for reuse in agriculture restricted irrigation
\end{abstract}

KEYWORDS: Constructed wetlands, wetlands, sewage treatment, reuse.

\footnotetext{
${ }^{1}$ Parte da Tese de Doutorado do $1^{\circ}$ autor intitulada: Avaliação do potencial de reuso agrícola do efluente de uma estação de tratamento de esgoto com alagados construídos.

2 Química, Departamento de Água e Esgoto de Bauru, Bauru/SP, e-mail: ggiafferis@ig.com.br
}

\footnotetext{
${ }^{3}$ Prof. Titular do Departamento de Engenharia Rural, FCA/UNESP, Botucatu/SP, e-mail: labaero@fca.unesp.br

${ }^{4}$ Prof. Doutor do Departamento de Engenharia Civil, FEB/UNESP, Bauru/SP, e-mail: eduoliv@ feb.unesp.br
} 


\section{INTRODUÇÃO}

Segundo o IBGE (2010), a população mundial atual está em torno de 6,1 bilhões de pessoas, com uma projeção de crescimento em nível global com taxa de 1,3\%, ou seja, de 77 milhões de pessoas a cada ano. Com o aumento da população, as necessidades relativas aos recursos hídricos e de saneamento crescem. No Brasil, $90 \%$ das residências têm acesso à água potável, mas somente $52,5 \%$ usufruem de esgotamento sanitário, e menos de $10 \%$ dos municípios possuem tratamento de esgoto.

Muitas pesquisas estão sendo realizadas no sentido de buscar novas tecnologias, com baixo custo, para tratar os esgotos sanitários. Nas regiões tropicais, onde encontram-se a maioria dos países em desenvolvimento, o tanque séptico convencional é a instalação mais frequentemente utilizada no tratamento primário, que funciona muito bem conjuntamente com o tratamento por sistemas de alagados construídos com fluxo subsuperficial (SACFS), que apresentam um bom desempenho na remoção de matéria orgânica e de nutrientes devido ao alto tempo de retenção e a uma extensa área de superfície do sedimento em contato com a água que flui (WATSON, 1989); apresenta baixos custos de implantação e manutenção, além de fácil operação, tornando-se adequado para implantação em pequenos aglomerados urbanos e vilas rurais carentes, sem infraestrutura de saneamento básico (BRASIL et al, 2005).

Os alagados construídos são sistemas artificialmente projetados, constituídos por lagoas ou canais, que podem conter plantas aquáticas fixas em substratos como areia, solo ou cascalho, onde ocorre a proliferação de biofilmes que agregam populações variadas de micro-organismos presentes nas águas residuárias (GARCIAet al, 2005). O substrato promove espaços vazios que servem de canais de vazão, facilitando o escoamento do esgoto ou da água poluída, de acordo com sua permeabilidade. Constitui aliado às raízes das macrófitas aquáticas, o local ideal para a remoção de nutrientes e para a formação do biofilme microbiano. $\mathrm{O}$ substrato deve ser colocado sobre uma proteção impermeável de lona, manta, asfalto ou argila compactada, que evita a contaminação do solo e a eventual infiltração até o lençol freático. Essas camadas permitem a contenção da água poluída no sistema (MARQUES, 1999; SALATI FILHO\&SALATI, 1999).

Campbell e Ogden (1999) também observam que os alagados construídos são cada vez mais reconhecidos, com um custo relativamente baixo e energeticamente eficiente, como meios naturais de tratamento de esgoto, de resíduos agrícolas e industriais, e águas pluviais. Ao mesmo tempo, oferecem potencial para benefícios múltiplos, tais como a possibilidade de integração dos sistemas alagados construídos em locais de lazer, promovendo habitat para diferentes seres vivos. Suas qualidades estéticas são superiores às dos sistemas de tratamento convencionais e o efluente tratado pode ser reciclado na irrigação de jardins ou retido em uma atraente lagoa para atrair a vida selvagem, além do benefício de se ter informações sobre os processos de alagados.

O reaproveitamento ou reuso da água é o processo pelo qual esta tratada ou não, é reutilizada para o mesmo ou outro fim. O efluente tratado, produzido em estações de tratamento de esgoto (ETE), pode ser utilizado como geração de energia ou refrigeração de equipamentos, em diversos processos industriais, pelas prefeituras e entidades que a utilizam na lavagem de ruas e pátios, no setor hoteleiro, na irrigação/rega de áreas verdes, na desobstrução de rede de esgotos e águas pluviais e na lavagem de veículos (BREGA; MANCUSO, 2003).

Diante do exposto, objetivou-se avaliar a eficiência na remoção de matéria orgânica e nitrogênios de três sistemas de alagados construídos, com tipos de plantas diferentes (Lírio do charco, Papiro gigante e Taboa), analisar quantitativa e qualitativamente os efluentes nas várias etapas do processo de tratamento, para verificar suas eficiências e a possibilidade de reuso do efluente final na agricultura.

\section{MATERIAL E MÉTODOS}

\section{1 Área de estudo}

A estação de tratamento de esgoto Tibiriçá, sob a responsabilidade do Departamento de Água e Esgoto de Bauru (DAE), está localizada a cerca de $20 \mathrm{~km}$ de distância da cidade de Bauru, no Distrito de Tibiriçá, com acesso pela Rodovia Marechal Rondon, sentido Bauru - Lins, na altura do km 360, entrada à esquerda na vicinal BRU - 15, coordenadas 7.539.968,615 m (N) e 683.424,746 m (E). De acordo com o IBGE (2010), a população do Distrito de Tibiriçá é de 1.004 hab atendidos por água potável, através de poço profundo, além de rede coletora e tratamento de esgoto. A população se concentra na área urbana, mas a agricultura é o maior meio de subsistência do local (DAE, 2010). A maior parte do distrito encontra-se na bacia do Rio Batalha, sendo que o afluente que recebe os despejos do efluente tratado é o córrego Barra Grande de Baixo, classificado como manancial Classe 2, de acordo com o Decreto Estadual 10.755/1997 e CONAMA 357/2005.

Em 2008, o sistema de tratamento de esgoto foi reformado pelo DAE, seguindo um projeto elaborado em convênio com a Faculdade de Engenharia Civil da UNESP, aproveitando todas as unidades já existentes e acrescentando mais uma etapa na sua operação. O processo adotado consiste em: gradeamento, caixa de areia (desarenação), calha Parshall, decantador primário, filtro anaeróbio de fluxo ascendente e alagados construídos.

Como estimativa das vazões da ETE, no período de agosto a novembrode 2010, considerou-se o consumo médio por economia, ou consumo per economia (CPE), utilizando os dados do banco de registros de consumos medidos pelo DAE. Como o Distrito apresenta 350 economias, cujo consumo médio mensal foi de 10.090 $\mathrm{m}^{3} / \mathrm{mês}$ em 2010, resultando na média de 23,06 
$\mathrm{m}^{3} / \mathrm{ec} / \mathrm{mês}$, isto é, uma média de $153,75 \mathrm{~L} \mathrm{hab}^{-1}$. dia ${ }^{-1}$, a vazão média diária foi calculada em de 3,80 L/s (13,68 $\mathrm{m}^{3} / \mathrm{h}$ ) ou $336,33 \mathrm{~m}^{3} /$ dia. A medição da vazão na Calha Parshall foi feita no período de maio a junho/2011, das 6:00 hs às 00:00 hs, ou seja, em um período de dezoito horas, e a vazão média obtida foi de $6,4 \mathrm{~L} / \mathrm{s}$, sendo considerada a vazão do período das 00:00 às 06:00 hs, como zero. Com os valores do período de 18 horas, calculou-se a vazão para 24 horas, e a média resultante foi de 4,8 L/s $\left(17,28 \mathrm{~m}^{3} / \mathrm{h}\right)$ ou 193,26 L.hab ${ }^{-1}$. $\mathrm{dia}^{-1}$. Um dos fatores observados para o aumento da vazão é a chegada de efluente não doméstico (característica de suinocultura), na estação por batelada, entre o período das 6:00 às 18:00 hs, não havendo um controle desta vazão, pois as medições foram pontuais.

No filtro anaeróbio, primeira etapa do tratamento, fez-se o projeto de modificação da laje de fundo, troca das tubulações internas e do enchimento de brita $n^{\circ} 4$ por poliestireno expandido (EPS) no formato geométrico côncavo para se pudesse ter uma operação do reator como manta de lodo. A primeira lagoa de polimento foi transformada em três leitos de alagados construídos, prevendo uma operação em duas Fases: a primeira, com fluxo subsuperficial horizontal (SACSH) e a segunda, com fluxo subsuperficial vertical e recirculação (SACSV). As especificações técnicas dos Sistemas de Alagados Construídos (SACs) da ETE Tibiriçá constam da Tabela 1 .

Tabela 1 - Especificações técnicas dos sistemas alagados construídos da ETE Tibiriçá.

\begin{tabular}{lll}
\hline Características físicas & Medidas & \\
\hline $\begin{array}{l}\text { Altura dos alagados construídos } \\
\text { (m) }\end{array}$ & 1,00 & \\
Altura útil do substrato (m) & 0,80 & \\
Largura útil (m) & 8,70 & \\
Comprimento útil (m) & 11,70 & \\
Profundidade útil (m) & 0,70 & \\
Volume útil de cada alagado (m3) & 25 & \\
Volume de vazios médio (\%) & 35 & (projetado) \\
Tempo de detenção hidráulica (h) & 2,33 & (real) \\
Taxas de aplicação superficial: & 1,52 & \\
& & (Fase 1) \\
Volumétrica (m3.m-2.dia-1) & 1,75 & (Fase 2) \\
& 1,36 & (Fase 1) \\
Carga orgânica (kg.m-2.dia-1) & 0,18 & (Fase 2) \\
& 0,15 & (Fase 1) \\
Carga amoniacal (kg.m-2.dia-1) & 0,031 & (Fase 2) \\
\hline
\end{tabular}

Na segunda etapa da operação do sistema, o efluente na caixa de passagem, foi encaminhado para os alagados através de bomba submersa, e um sistema automatizado com três eletroválvulas, que são acionadas intercaladamente para cada alagado, onde o efluente percolado da parte inferior foi recirculado à parte superior, completando assim ciclos de percolação, operando como alagados de fluxo subsuperficial vertical. As espécies vegetais plantadas nos alagados foram: Iris pseudocorus L., conhecida também por lírio-do-charco (alagado 1); Cyperus papyrus, o papirus (alagado 2) e Typha latifolia ou taboa (alagado 3), por serem plantas macrófitas mais usadas em sistemas de alagados construídos no Brasil.

As vazões dos três alagados foram direcionadas à lagoa de polimento, para dar continuidade ao tratamento e as amostras do efluente final foram coletadas nesta etapa. Os resultados analisados nesta pesquisa foram obtidos a partir do monitoramento das etapas em operação da ETE Tibiriçá, executados pelo laboratório de águas residuárias, no período de agosto a novembro de 2010 e maio e junho de 2011 .

As coletas foram realizadas com periodicidade semanal, às quartas-feiras no mesmo horário e analisadas as seguintes variáveis: $\mathrm{pH}$, turbidez, temperatura, demanda bioquímica de oxigênio (DBO5,20), demanda química de oxigênio (DQO), oxigênio dissolvido (OD), nitrogênio amoniacal (N-NH3), nitrogênio total Kjeldhal (NTK), nitrogênio orgânico (NTK - N-NH3), nitrogênio nitrato (N-NO3-), nitrogênio nitrito $(\mathrm{N}-\mathrm{NO} 2)$ em todas as etapas, e as amostras de coliformes totais e coliformes fecais (termotolerantes) foram analisadas somente no efluente final.

\section{RESULTADOS E DISCUSSÃO}

A operação da Fase 1 ocorreu de 18/08/2010 a 10/11/2010 com o sistema de alagados construídos de fluxo horizontal (SACFH) e na Fase 2 de 11/05/2011 a 29/06/2011 com sistema de fluxo vertical (SACFV). Os resultados de $\mathrm{pH}$, temperatura e oxigênio dissolvido encontrados no período analisados, na Fase 1 e 2 de operação estão na Tabela 2. 
Tabela 2 - Valores de temperatura e $\mathrm{pH}$; concentração média $\left(\mathrm{mg} \cdot \mathrm{L}^{-1}\right)$ de oxigênio dissolvido do esgoto bruto, do efluente do filtro anaeróbio, dos sistemas alagados construídos na Fase 1 e 2 e do efluente final, no período de agosto a novembro/2010 e maio a junho/2011.

\begin{tabular}{|c|c|c|c|c|c|c|c|c|c|c|}
\hline \multirow{3}{*}{ Parâmetro } & \multirow{3}{*}{$\begin{array}{l}\text { Esgoto } \\
\text { bruto }\end{array}$} & \multirow{2}{*}{\multicolumn{2}{|c|}{$\begin{array}{c}\text { Filtro } \\
\text { Anaeróbio }\end{array}$}} & \multicolumn{6}{|c|}{ Efluente dos Alagados Construídos } & \multirow{3}{*}{ 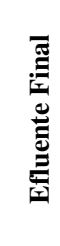 } \\
\hline & & & & \multicolumn{2}{|c|}{$\begin{array}{l}\text { Alagado 1(Lírio } \\
\text { Charco) }\end{array}$} & \multicolumn{2}{|c|}{$\begin{array}{c}\text { Alagado 2 } \\
\text { (Papirus) }\end{array}$} & \multicolumn{2}{|c|}{$\begin{array}{l}\text { Alagado } 3 \\
\text { (Taboa) }\end{array}$} & \\
\hline & & $\approx \frac{\mathscr{g}}{5}$ & స & 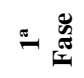 & 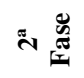 & $\approx \frac{\mathscr{\sigma}}{5}$ & స̃ & $\approx$ 漓 & స̃ & \\
\hline Temperatura & 23,4 & 26,9 & 24,5 & 25,6 & 24,4 & 25,5 & 24,6 & 24,8 & 24,9 & 26,0 \\
\hline $\mathrm{pH}$ & 6,60 & 6,41 & 6,09 & 6,60 & 6,13 & 6,59 & 6,18 & 6,58 & 6,13 & 6,49 \\
\hline OD & 1,24 & 1,89 & 1,14 & 2,65 & 1,55 & 2,88 & 2,20 & 2,95 & 2,05 & 3,46 \\
\hline
\end{tabular}

A temperatura se manteve na média dos $24^{\circ} \mathrm{C}$, o que propicia a eficiência do tratamento de esgoto biológico. Segundo Hammer; Knight (1994) as temperaturas ótimas para que ocorra a desnitrificação variam entre $25^{\circ} \mathrm{C}$ e $65^{\circ} \mathrm{C}$.

Durante a Fase 1, observa-se que o pH se manteve na faixa entre 6,41 a 6,60 , próximo ou pouco ácido, mas próximo a neutralidade, em todas as etapas do processo (Tabela 2). No efluente final o $\mathrm{pH}$ foi igual a 6,49. Segundo Metcalf e Eddy (1991) o pH ótimo para a desnitrificação encontra-se entre 6,5 e 9,0. A Lei Estadual, nos padrões de emissão, exige que o pH permaneça entre 5,0 e 9,0 para efluentes que poderão ser lançados direta ou indiretamente nos corpos de água.

As concentrações médias de OD encontradas no período de agosto a novembro/2010 demonstraram elevado teor de compostos orgânicos favorecendo a nitrificação, portanto resultando em baixos teores de Oxigênio dissolvido. Somente nos alagados construídos ocorre um pequeno aumento do $\mathrm{OD}$, em razão da retenção da matéria orgânica nos leitos de brita e assim favorecendo um aumento de oxigênio através do fluxo vertical dos SACs. Após a passagem do efluente de saída dos alagados, passando pela lagoa de polimento, verifica-se um aumento para $3,46 \mathrm{mg} / \mathrm{L}$ de OD no efluente final (Tabela 2).

Tabela 3 - Concentração média $(\mathrm{mg} / \mathrm{L})$ de DBO e DQO do esgoto bruto, dos efluentes do filtro anaeróbio e

\section{Matéria Orgânica}

\section{a.1) Demanda bioquímica de oxigênio}

No dia 20/10 (Fase 1) ocorreu a entrada do esgoto bruto, com muitos sólidos em suspensão, demonstrado o valor de $666 \mathrm{mg} / \mathrm{L}$ DBO e após esta ocorrência retorna à média de $400 \mathrm{mg} / \mathrm{L}$ (Figura 1)

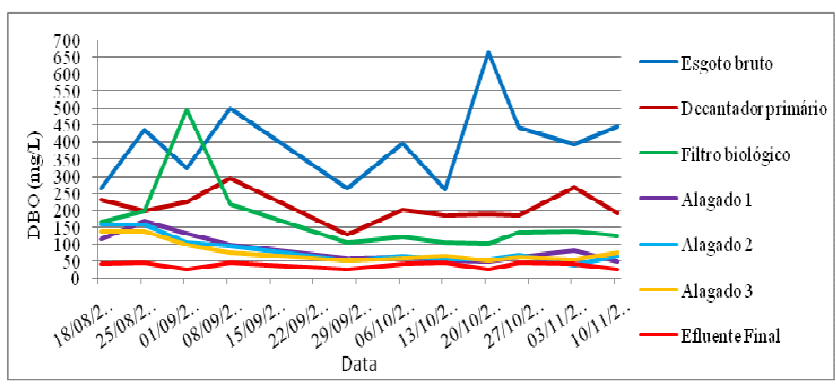

Figura 1 - Resultados de DBO5,20 dos efluentes da ETE Tibiriçá na Fase 1 ( $\mathrm{mg} / \mathrm{L}$ ).

A DBO do efluente do filtro anaeróbio se manteve na média de $172 \mathrm{mg} / \mathrm{L}$ e no dia 01/09 teve um pico de 494 $\mathrm{mg} / \mathrm{L}$. Os SACs se mantiveram numa faixa média de 50 $\mathrm{mg} / \mathrm{L}$ demonstrando que no início da operação a remoção de matéria orgânica esteve em $50 \%$ de eficiência (Tabela 3). Estes resultados obtidos para DBO podem ser atribuídos aos processos de filtração e adsorção, aos processos biológicos que ocorrem com o meio suporte e biofilme no início da operação do sistema.

\section{alagados construídos na primeira e segunda Fase da operação do sistema e eficiência de remoção (\%).} Resultados $\left(\mathrm{mg}^{\left.-\mathrm{L}^{-1}\right)}\right.$

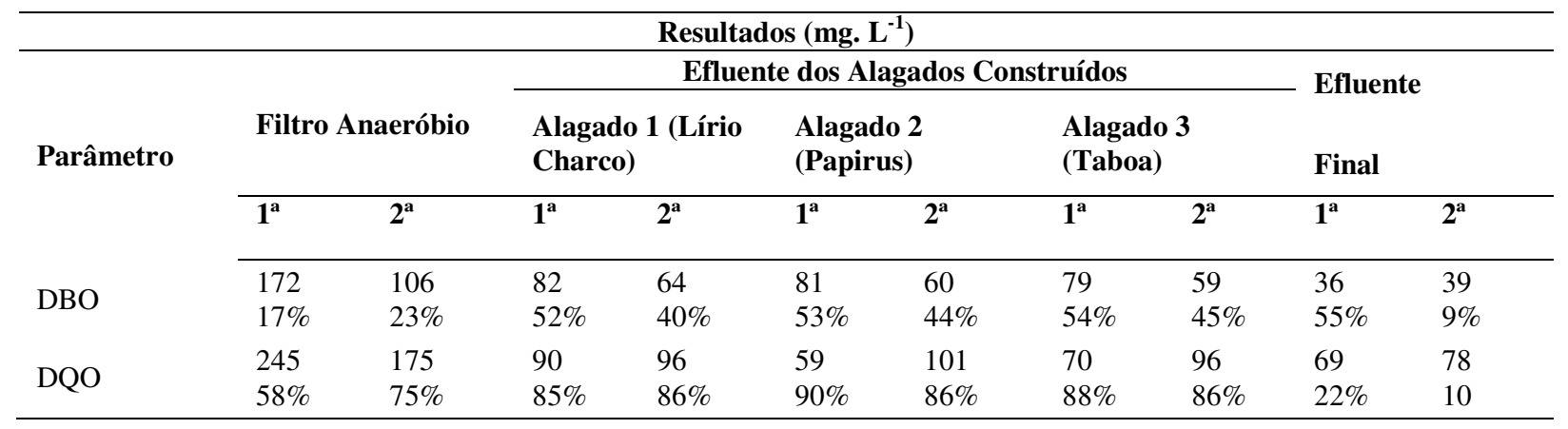


Na Fase 2 de operação os três SACs mantiveram uma média de remoção da DBO. No alagado 1 foram de 64 $\mathrm{mg} / \mathrm{L}$, no 2, a média foi de $60 \mathrm{mg} / \mathrm{L}$, mesmo quando o sistema foi parado para manutenção em 08/06 e no alagado 3 foram de $59 \mathrm{mg} / \mathrm{L}$,considerando uma eficiência de remoção de 40, 44 e 45\%, repectivamente.

Observa-se que a remoção da matéria orgânica ocorre em concentrações médias semelhantes nos três tipos de macrófitas utilizadas. Observa-se que pontualmente, em algumas fases como no período de crescimento das plantas, a taboa e o lírio do charco atingem maior remoção da matéria orgânica.

As concentrações médias de DBO do efluente final, neste período, se manteve com $39 \mathrm{mg} / \mathrm{L}$, atendendo as exigência do Decreto Estadual 8468/76 e CONAMA 430/2011 que exige no máximo de $60 \mathrm{mg} / \mathrm{L}$ para padrões de lançamento de efluentes e na Fase 1 com 36 mg/L também atendendo a legislação.

\section{a.2) Demanda química de oxigênio}

Quanto aos valores de DQO foi registrada uma concentração média no esgoto bruto de $640 \mathrm{mg} / \mathrm{L}$, considerando-se a operação nas Fases1 e 2. Observou-se que manteve uma relação DQO/DBO5,20 de quase 2:1, o que favorece o sistema. Segundo a CETESB (2010), os valores muito elevados desta relação indicam grandes possibilidades de insucesso, uma vez que a fração biodegradável torna-se pequena, tendo-se ainda $o$ tratamento biológico prejudicado pelo efeito tóxico sobre os micro-organismos exercido pela fração não biodegradável. Na Fase 1 ocorreu um aumento da DQO no dia 20/10, com valor de $1300 \mathrm{mg} / \mathrm{L}$, mas em todo o restante do processo obteve-se uma remoção satisfatória, onde o efluente final resultou em $36 \mathrm{mg} / \mathrm{L}$ de DBO e 69 $\mathrm{mg} / \mathrm{L}$ DQO.

No esgoto bruto a DQO, na segunda Fase da operação, teve uma concentração média de $696 \mathrm{mg} / \mathrm{L}$, tendo sido reduzida no decantador primário para $291 \mathrm{mg} / \mathrm{L}$, ou seja, com uma eficiência de remoção de $58 \%$. Nos SACs, a DQO se manteve nas médias de $96 \mathrm{mg} / \mathrm{L}$ onde foi cultivado o lírio-do-charco, $101 \mathrm{mg} / \mathrm{L}$ no $\mathrm{SAC}$ com papirus e $96 \mathrm{mg} / \mathrm{L}$ no SAC com taboa, ocorrendo picos no dia 20/06/2011. A eficiência de remoção foi de $86 \%$, nos três tipos de plantas (Tabela 3). Os resultados obtidos na remoção de DQO estiveram acima dos encontrados por Souza et al. (2000), de 79 a $84 \%$ de remoção, e próximos dos resultados obtidos por Brasil et al. (2005), de 87 a 90\% de remoção em SACs com Typha sp.

\subsection{Nitrogênios}

Tabela 5 - Concentração média $(\mathrm{mg} / \mathrm{L})$ das formas nitrogenadas presentes no efluente do filtro anaeróbio, alagados construídos e efluente final, e eficiência de remoção (\%) do NTK, na primeira e segunda Fase da operação do sistema.

\begin{tabular}{|c|c|c|c|c|c|c|c|c|c|c|}
\hline \multirow[b]{3}{*}{ Parâmetro } & \multirow{2}{*}{\multicolumn{2}{|c|}{ Filtro Anaeróbio }} & \multicolumn{6}{|c|}{ Efluente dos Alagados Construídos } & \multirow{2}{*}{\multicolumn{2}{|c|}{$\begin{array}{l}\text { Efluente } \\
\text { Final }\end{array}$}} \\
\hline & & & \multicolumn{2}{|c|}{ Alagado 1} & \multicolumn{2}{|c|}{$\begin{array}{l}\text { Alagado 2 } \\
\text { (Papirus) }\end{array}$} & \multicolumn{2}{|c|}{$\begin{array}{l}\text { Alagado } 3 \\
\text { (Taboa) }\end{array}$} & & \\
\hline & $\mathbf{1}^{\mathrm{a}}$ & $2^{\mathbf{a}}$ & $\mathbf{1}^{\mathbf{a}}$ & $2^{\mathbf{a}}$ & $1^{\mathrm{a}}$ & $2^{\mathbf{a}}$ & $\mathbf{1}^{\mathbf{a}}$ & $2^{\mathbf{a}}$ & $\mathbf{1}^{\mathbf{a}}$ & $2^{\mathrm{a}}$ \\
\hline NTK & $\begin{array}{l}42,36 \\
2 \%\end{array}$ & $\begin{array}{l}21,56 \\
26 \%\end{array}$ & $\begin{array}{l}36,84 \\
13 \%\end{array}$ & $\begin{array}{l}25,61 \\
0 \%\end{array}$ & $\begin{array}{l}35,55 \\
16 \%\end{array}$ & $\begin{array}{l}25,67 \\
0 \%\end{array}$ & $\begin{array}{l}45,43 \\
0 \%\end{array}$ & $\begin{array}{l}26,02 \\
0 \%\end{array}$ & $\begin{array}{l}33,87 \\
14 \%\end{array}$ & $\begin{array}{l}25,49 \\
1 \%\end{array}$ \\
\hline N Orgânico & 13,50 & $-3,41$ & 9,22 & $-0,09$ & 8,89 & 1,24 & 16,54 & 3,35 & 5,74 & 2,58 \\
\hline $\begin{array}{l}\text { Nitrogênio } \\
\text { amoniacal }\end{array}$ & 28,76 & 24,97 & 27,63 & 25,70 & 26,66 & 24,43 & 28,89 & 22,67 & 28,13 & 22,91 \\
\hline $\begin{array}{l}\text { Nitrogênio } \\
\text { nitrito }\end{array}$ & 0,004 & 0,006 & 0,003 & 0,005 & 0,002 & 0,006 & 0,003 & 0,006 & 0,005 & 0,005 \\
\hline $\begin{array}{l}\text { Nitrogênio } \\
\text { nitrato }\end{array}$ & 3,3 & 4,4 & 2,3 & 3,2 & 2,1 & 1,4 & 2,3 & 2,9 & 2,3 & 3,1 \\
\hline
\end{tabular}

\section{b1) Nitrogênio total Kjeldhal}

Para as concentrações de nitrogênio total Kjeldhal (NTK) verificou-se uma concentração média de 56,52 $\mathrm{mg} / \mathrm{L}$ no esgoto bruto. No filtro anaeróbio a concentração foi de $42,36 \mathrm{mg} / \mathrm{L}$ na primeira Fase. No alagado com lírio-do-charco, a concentração média foi de $36,84 \mathrm{mg} / \mathrm{L}$, no alagado 2 de $35,55 \mathrm{mg} / \mathrm{L}$ e no alagado 3 de 45,43 mg/L (Tabela 4).

Verificou-se, na Fase 2 da operação dos SACs, que as concentrações médias de nitrogênio total foram de 25,61, 25,67 e 26,02 mg/L, respectivamente para 1, 2 e 3, sendo estes resultados muito inferiores aos resultados obtidos por Brasil et al (2005), de $24 \%$, em pesquisa realizada em alagados com leito de Typha sp. O efluente final analisado nas Fases 1 e 2 demonstraram, respectivamente, a concentração média de $33,87 \mathrm{mg} / \mathrm{L}$ e 25,49 mg/L NTK.

A eficiência de remoção de $\mathrm{N}$ total em tratamento biológico, segundo Metcalf e Eddy (1991), depende dos processos de transformação atuantes, dos quais a nitrificação pode remover de 90 a $95 \%$ do nitrato e a assimilação por parte dos micro-organismos, de 40 a $70 \%$ de $\mathrm{N}$ amoniacal. Assim, os resultados obtidos nesta pesquisa, indicam que o processo de nitrificação não aconteceu. Os fatores que afetaram a eficiência do 
sistema, primeiramente, são decorrentes do breve período de funcionamento dos SACs com fluxo horizontal (que foi de 82 dias), ficando 150 dias parado por problemas operacionais. No segundo momento, os SACs retornaram operando com fluxo vertical, em maio/2011, por um período de 48 dias, provavelmente um período não suficiente para a retomada da eficiência do sistema.

\section{b2) Nitrogênio amoniacal}

A concentração média de nitrogênio amoniacal encontrada no esgoto bruto foi de 31,62 mg/L e 28,69 $\mathrm{mg} / \mathrm{L}$, considerando-se todo o período de análise neste trabalho. O processo de amonificação ocorre a partir da degradação da matéria orgânica nitrogenada, dissolvida ou particulada, com produção de amônia, mediada por organismos heterótrofos (conversão do N-orgânico a Namoniacal). Aparentemente ocorre no filtro anaeróbio, onde as concentrações de N-NH3 são maiores. No início da operação houve uma redução do $\mathrm{N}$ amoniacal para 28,76 mg/L no filtro anaeróbio. Observou-se um aumento das concentrações de N-NH3 no filtro anaeróbio após 15 dias da operação (em torno de 15\%), as quais se mantiveram nesta faixa até o final desta pesquisa. No alagado com fluxo horizontal, com líriosdo-charco, a concentração do nitrogênio amoniacal foi de $27,63 \mathrm{mg} / \mathrm{L}$. No alagado com papirus, registrou-se uma concentração N-NH3 de 26,66 mg/L e no alagado com taboa, de $28,89 \mathrm{mg} / \mathrm{L}$. A remoção observada nesta Fase, pode acontecer pelo processo assimilatório das bactérias presentes no biofilme do substrato, que incorporam a N-NH4- na sua estrutura fisiológica celular e das macrófitas presentes no sistema (Tabela 4).

$\mathrm{Na}$ segunda Fase de operação, as concentrações encontradas no decantador que as concentrações de $\mathrm{N}$ NH3 s não ocorreram, notando-se que no alagado 1 houve um pequeno aumento para $25,70 \mathrm{mg} / \mathrm{L}$. A concentração de N-NH3 no alagado com do com papirus manteve-se com $24,43 \mathrm{mg} / \mathrm{L}$ e no alagado com taboa de $22,67 \mathrm{mg} / \mathrm{L}$. O efluente final demonstrou concentrações de $28,13 \mathrm{mg} / \mathrm{L}$ na Fase 1 e na Fase 2 de 22,91 mg/L. Segundo a Resolução CONAMA 397/2008, os valores máximos permissíveis para o nitrogênio amoniacal é 20 $\mathrm{mg} / \mathrm{L} \mathrm{N}$, para os padrões de lançamentos de efluentes, estando acima do permitido.

\section{b3) Nitrogênio nitrito}

O nitrogênio nitrito encontrado no esgoto bruto da estação manteve-se quase sem alteração dos valores em todas as etapas do processo e nas duas Fases.

\section{b4) Nitrogênio nitrato}

Em relação ao nitrogênio nitrato, constatou-se que nos alagados construídos, a concentração média foi de 2,3 $\mathrm{mg} / \mathrm{L}$ no alagado $1,2,1 \mathrm{mg} / \mathrm{L}$ no alagado 2 e $2,3 \mathrm{mg} / \mathrm{L}$ no alagado 3. Notou-se que no leito com lírio-do-charco (alagado 1) a concentração média manteve-se estável por todo o período de estudo. O leito com papirus (alagado
2), inicialmente, indicou uma concentração média menor, elevando-se após 35 dias de operação até 60 dias de operação. O efluente final, nesta fase, obteve concentração média de $2,3 \mathrm{mg} / \mathrm{L}$.

Os SACs, na segunda Fase de operação, apresentaram concentrações médias de 3,2, 1,4 e 2,9 mg/L de N-NO3-, respectivamente. As concentrações de N-NO3-refletiram o processo de nitrificação. Quando as concentrações de amônia nos SACs diminuiram, as concentrações de nitrato aumentaram (Tabela 4), indicando a ocorrência de conversão da amônia a nitrato. Nesta Fase 2 da operação, as plantas dos SACs passaram por processo de poda, o que provavelmente acelerou a absorção do nitrogênio.

\section{b5) Balanço de nitrogênio}

Na Figura 2, que mostra o balanço de nitrogênio, na Fase 1 , observa-se que o nitrogênio amoniacal, que compõe $60 \%$ da fração de nitrogênio, ficou na faixa de 25 a 30 $\mathrm{mg} / \mathrm{L}$. Para o nitrito e o nitrato ocorrem em pequenas quantidades e representam menos de $1 \%$ do nitrogênio total; as concentrações média do nitrito, foram de 0,005 $\mathrm{mg} / \mathrm{L}$ e as do nitrato ficaram na faixa de 2,8 a $6,0 \mathrm{mg} / \mathrm{L}$, enquanto as do NTK permaneceram na faixa de 30 a 45 $\mathrm{mg} / \mathrm{L}$.

O predomínio do nitrogênio amoniacal sugere que as condições eram redutoras, mas para isso o pH deveria estar em uma faixa mais ácida do que os valores encontrados. Como não foi possível medir o potencial redox (Eh), pois o laboratório do DAE não possui o eletrodo específico, ficou difícil confirmar se as condições apresentadas no meio eram aeróbias, anóxicas ou anaeróbias.

Notou-se na Fase 1 que as concentrações de $\mathrm{N}$ orgânico estiveram mais altas nas primeiras etapas do processo e nos SACs apresentaram uma diminuição similar nos sistemas 1 e 2 e com acréscimo no alagado 3. No efluente final houve um decréscimo. $\mathrm{O} \mathrm{N}$ amoniacal permaneceu elevado, obtendo-se uma pequena redução no alagado 1 e 2 e elevando-se no alagado 3 , ocorrendo um decréscimo no efluente final. O nitrogênio nitrito $(\mathrm{N}$ $\mathrm{NH}_{2}$ ) manteve-se em valores abaixo de zero em todas as etapas.

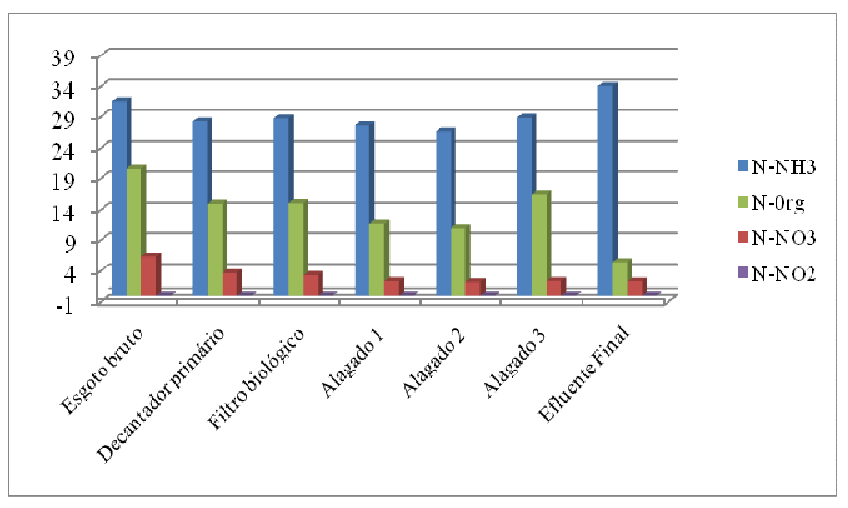

Figuras 2 - Resultados do balanço de nitrogênio (mg/L) na ETE Tibiriçá, na Fase 1. 
Na Fase 2, observou-se que o $\mathrm{N}$ amoniacal esteve elevado até o filtro anaeróbio. Ocorreu um aumento no alagado 1, e houve redução nos alagados 2 e 3 . No efluente final houve um pequeno acréscimo (Figura 3).

Quanto ao N orgânico observou-se elevada redução em todas as etapas do processo, principalmente nos sistemas de alagados, onde a melhor eficiência foi constatada no alagado 1 (Lírio-do-charco). O nitrogênio nitrito ( $\mathrm{N}$ $\mathrm{NH} 2$ ) manteve-se em valores abaixo de zero em todas as etapas.

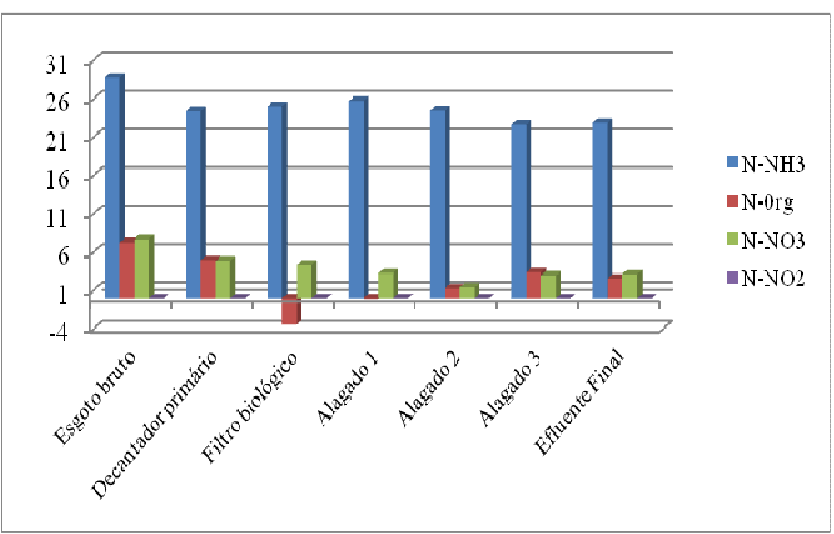

Figuras 3 - Resultados do balanço de nitrogênio (mg/L)na ETE Tibiriçá, na Fase 2.

As concentrações de nitrogênio encontradas no efluente favorecem o reuso na irrigação agrícola, de forma adequada proporcionando economia de fertilizante e maior proteção do corpo d'água, visto que a matéria orgânica, no solo, exerce efeitos sobre as propriedades físicas, químicas e biológicas, beneficiando a fertilidade e reduzindo custos e boa quantidade de nutrientes, como de $\mathrm{N}$ e $\mathrm{P}$.

\subsection{Micro-organismos}

Quanto aos parâmetros microbiológicos, somente foi analisado no efluente final do processo de tratamento de esgoto. Os resultados do monitoramento na Fase 1 mostraram a presença de coliformes totais (CT) e coliformes termotolerantes ou fecais (CF) no efluente final da estação, com densidades de micro-organismos elevadas, apresentando uma concentração média de 8,69 x $10^{6}$ UFC $100 \mathrm{~mL}^{-1}$ para coliformes totais (CT) e de $9,95 \times 10^{5}$ UFC $100 \mathrm{~mL}^{-1}$ para coliformes fecais (CF). $\mathrm{Na}$ operação da Fase 2, observou-se uma concentração média de $2,43 \times 10^{7} \mathrm{UFC} 100 \mathrm{~mL}^{-1}$ para coliformes totais e de $8,55 \times 10^{6}$ UFC $100 \mathrm{~mL}^{-1}$ para coliformes fecais. Estes resultados ficaram acima da concentração de $1 x$ $10^{2} .100 \mathrm{~mL}^{-1}$, valor máximo recomendado pela OMS para uso na irrigação de vegetais a serem consumidos crus.

Pela contagem de coliformes totais e dos fecais, os números elevados acima de $10^{6}$ e $10^{5}$, respectivamente, mostram que o uso na fertirrigação por aspersão em culturas não é uma boa alternativa, pois coloca em risco à saúde pública, a menos que o efluente final seja submetido a um processo de desinfecção.

\subsection{Eficiência da estação de tratamento de esgoto}

A concentração média de DBO no esgoto bruto foi de $399 \mathrm{mg} / \mathrm{L}$ na Fase 1 e $370 \mathrm{mg} / \mathrm{L}$ na Fase 2. A DQO acompanhou os valores na relação 2:1, com concentrações de $585 \mathrm{mg} / \mathrm{L}$ e $696 \mathrm{mg} / \mathrm{L}$, como demonstrado anteriormente. A concentração de DBO no efluente final nas Fases 1 e 2 foram de 36 e 39 mg/L, respectivamente.

Tabela 5 - Concentrações médias de DBO e DQO (mg/L) e eficiência de remoção média (\%) obtidas no esgoto bruto e efluente final durante a operação do sistema.

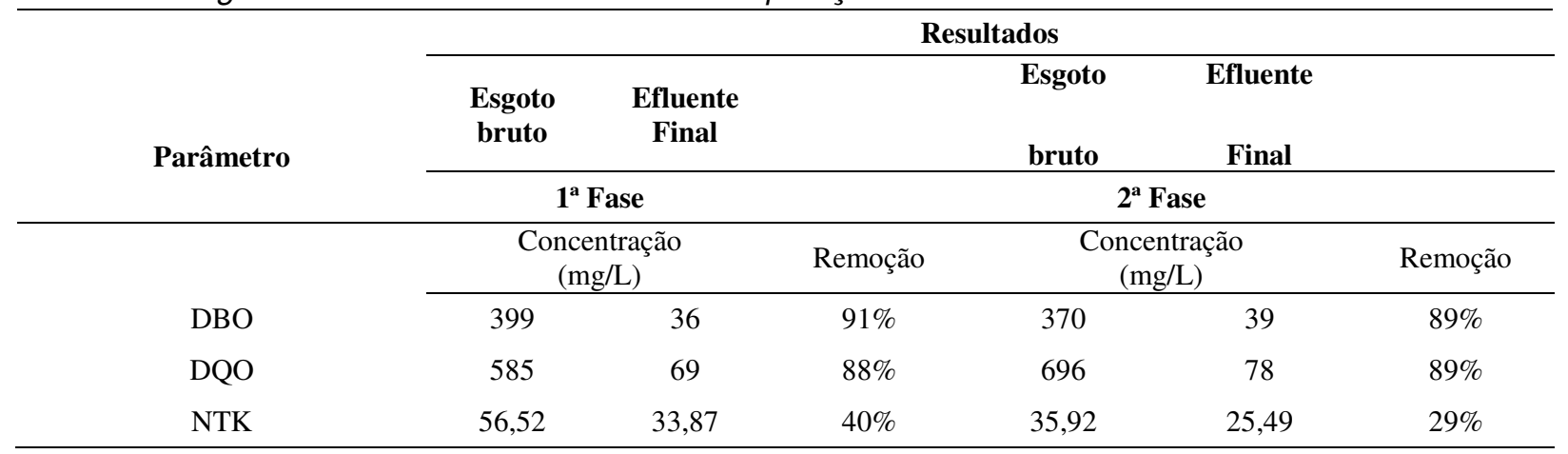

Deve-se considerar que, durante todo o período de estudo, a eficiência de DBO na Fase 1 foi de $91 \%$ e na Fase 2 de $89 \%$, considerando o esgoto bruto e o efluente final da estação, enquanto a DQO foi $88 \%$ e $89 \%$, respectivamente, atendendo as exigências para lançamento de efluente, conforme legislação vigente (Tabela 5).
As concentrações médias de NTK foram de $56,52 \mathrm{mg} / \mathrm{L}$ e 35,92 $\mathrm{mg} / \mathrm{L}$ nos dois períodos analisados, respectivamente. Observaram-se poucas variações na concentração do esgoto bruto em relação a este parâmetro, recebendo sempre altas concentrações. Notou-se que ocorreu uma baixa eficiência de remoção dos nitrogênios, no processo em geral, mas observa-se na 
Tabela 4 que houve uma eficiência de $40 \%$ na Fase1 e de $29 \%$ na Fase 2.

\section{CONCLUSÃO}

Nos resultados analisados da demanda bioquímica de oxigênio (DBO) demonstraram que os efluentes dos sistemas de alagados construídos de fluxo horizontal, na Fase 1 de operação obtiveram remoção satisfatória. Os resultados de remoção para matéria orgânica observados nos três tipos de macrófitas utilizadas nos alagados, foram similares não demonstrando diferenciação quanto s espécies.

Quanto à remoção de nitrogênio amoniacal, a eficiência ficou abaixo do esperado, não atendendo a legislação que exige lançamentos com até $20 \mathrm{mg} / \mathrm{L}$. Nos efluentes produzidos no processo, constatou-se concentrações elevadas de NTK, orgânico e amoniacal. Uma providência para melhoria da remoção das cargas de $\mathrm{N}$ e $\mathrm{P}$ seria aumentar o tempo de detenção hidráulica (TDH) e maior oxigenação do sistema.

Com os resultados de nitrogênios obtidos nos efluentes dos SACs, conclui-se que o sistema também está funcionando como tratamento secundário, ou seja, complementando o filtro anaeróbio, não fazendo seu papel como foi projetado, para ser uma etapa de tratamento terciário.

As concentrações de nitrogênio encontradas no efluente favorecem o reuso na irrigação agrícola.

Os coliformes fecais e totais ficaram elevados, não sendo recomendado para o uso na irrigação por aspersão.

\section{REFERÊNCIAS}

BRASIL, M.S.; MATOS, A.T.; SOARES, A.A.; FERREIRA, P.A. Qualidade do efluente de sistemas alagados construídos, utilizados no tratamento de esgoto doméstico. Revista Brasileira de Engenharia Agrícola e Ambiental, Campina Grande, v.9, p. 133-137, 2005. Suplemento.

BRASIL. Ministério do Meio Ambiente. Conselho Nacional do Meio Ambiente - CONAMA. Resolução 430, 13 de maio de 2011. Dispõe sobre as condições e padrões de lançamento de efluentes, complementa e altera a Resolução no 430, de 13 de maio de 2011,. Brasília, DF, 2011. Disponível em:

<http://www.mma.gov.br/port/conama/legiabre.cfm?codl egi=646>. Acesso em: 11 jan. 2012.

BRASIL. Ministério do Meio Ambiente. Conselho Nacional do Meio Ambiente - CONAMA. Resolução 39703 de abril de 2008. Altera o inciso II do § 4o e a Tabela X do $\S 5^{\circ}$, ambos do art.34 da Resolução do Conselho Nacional do Meio Ambiente-CONAMA ${ }^{\circ}$ 357 , de 2005, que dispõe sobre a classificação dos corpos de água e diretrizes ambientais para o seu enquadramento, bem como estabelece as condições e padrões de lançamento de efluentes. Brasília, DF, 2005. Disponível em:

<http://www.mma.gov.br/port/conama/legiabre.cfm?codl egi=563>. Acesso em: 12 jan. 2012.

BREGA FILHO; MANCUSO, P. C. S. Conceitos de reúso de água. MANCUSO, P. C. S; SANTOS, H. F. (Ed.). Reúso de água. Barueri, SP: MANOLE, 2003. p. 21-36.

CAMPBELL, C.S.; OGDEN,M. Constructedwetlands in thesustainablelandscape. New York: John Wiley, 1999. 270p.

\section{DEPARTAMENTO DE ÁGUA E ESGOTO DE}

BAURU. DAE. Autarquia Municipal de Bauru. Prefeitura Municipal de Bauru. 2010.

HAMMER, D.A.; KNIGHT, R.L.

Designingconstructedwetlands for nitrogenremoval.Water Science and Technology, London, v.29, n.4, p.15-27, 1994.

INSTITUTO BRASILEIRO DE GEOGRAFIA E ESTATÍSTICA. Censo Demográfico de 2010.

População do Brasil é de 190.732.694 pessoas. Instituto Brasileiro de Geografia e Estatística.Sala de imprensa. Brasília, DF, 2010. Disponível em: http://www.ibge.gov.br/censo2010/.

GARCÍA, J.,MORATÓ, J.;BAYONA, J.M.Humedalesconstruidos para eltratamiento de aguas residuales. QUIMICA UNIVERSAL. Vol.8: 8487. ISSN: 1697-8854. 2005.

MARQUES, D.M. Terras úmidas construídas de fluxo subsuperficial. In: CAMPOS, J. R. Tratamento de esgotos sanitários por processo anaeróbio e disposição controlada no solo. Rio de Janeiro: ABES, 1999. p. 409 - 435.

METCALF; EDDY.Wastewater engineering treatment, disposal and reuse. 3. ed. New York: McGraw-Hill, 1991. 1334 p.

SALATI FILHO, E.; SALATI, E. Wetland projects developed in Brazil. Water Science and Technology, London: IWA, v.40, n.3, p. 19-25, 1999.

SÃO PAULO (Estado). Secretaria de Estado do Meio Ambiente. Companhia Ambiental do Estado de São Paulo - CETESB. Decreto n. 8468, 08 de setembro de 1976. Aprova o Regulamento da Lei n ${ }^{\circ} 997$, de 31 de maio de 1976, que dispõe sobre a prevenção e o controle da poluição do meio ambiente. Disponível em: <http://www.cetesb.sp.gov.br/Institucional/documentos/ Dec8468.pdf>. Acesso em: 10dez. 2010.

SOUSA, J.T.; VAN HAANDEL, A.C.; CONSENTINO, P.R.S.; GUIMARAES, A.V.A. Pós-tratamento de efluente de filtro anaeróbio utilizando sistemas "wetlands" construídos. 2000. Revista Brasileira de 
Engenharia Agrícola e Ambiental, Campina Grande, v.4, n.1, p. 87-91, 2000.

WATSON, J. T. et al. Performance expectations and loading rates for constructed wetlands. In: WATSON, J.T. et al. Constructed wetlands for wastewater treatment. Chelsea: Lewis, 1989. p. 319-351. 